\title{
Applications of High-Efficiency Abrasive Process with CBN Grinding Wheel
}

\author{
Yali Hou ${ }^{1}$, Changhe $\mathrm{Li}^{1}$, Yan Zhou ${ }^{2}$ \\ ${ }^{1}$ College of Mechanical Engineering, Qingdao Technological University, Qingdao, China \\ ${ }^{2}$ Department of Mechanical Engineering, Qingdao Feiyang Vocational\&Technical College, Qingdao, China \\ Email:Sy_lichanghe@163.com,houyalichina@163.com,qingpiwuzi@163.com \\ Received October 8, 2009; revised November 20, 2009; accepted November 26, 2009
}

\begin{abstract}
High-efficiency abrasive process with CBN grinding wheel is one of the important techniques of advanced manufacture. Combined with raw and finishing machining, it can attain high material removal rate like turning, milling and planning. The difficult-to-grinding materials can also be ground by means of this method with high performance. In the present paper, development status and latest progresses on high-efficiency abrasive machining technologies with CBN grinding wheel relate to high speed and super-high speed grinding, quick point-grinding, high efficiency deep-cut grinding, creep feed deep grinding, heavy-duty snagging and abrasive belt grinding were summarized. The efficiency and parameters range of these abrasive machining processes were compared. The key technologies of high efficiency abrasive machining, including grinding wheel, spindle and bearing, grinder, coolant supplying, installation and orientation of wheel and workpiece and safety defended, as well as intelligent monitor and $\mathrm{NC}$ grinding were investigated. It is concluded that high efficiency abrasive machining is a promising technology in the future.
\end{abstract}

Keywords: CBN Grinding, Super-High Speed Grinding, High Efficiency Deep-Cut Grinding, Quick-Point Grinding

\section{Introduction}

With the increasing requirements of modern industrial technology and high-performance technological products in respect of part precision, surface integrity, machining efficiency and batch-quality stability, grinding has played a more and more important role. It becomes an important part of advanced machining technology and equipment, and is a research frontier in manufacturing science.

Generally, the wheel velocity between 30 and $35 \mathrm{~m} / \mathrm{s}$ is defined as conventional grinding; The wheel speed exceeding 45 to $50 \mathrm{~m} / \mathrm{s}$ is defined as high speed grinding; The wheel speed between 150 and $180 \mathrm{~m} / \mathrm{s}$ or higher is defined as Super-high Speed Grinding.

The specific material removal rate in conventional grinding is less than $10 \mathrm{~mm}^{3} / \mathrm{mm}$.s. It has long been a pursuit in academe and engineering field to improve grinding efficiency. There are three approaches: 1) adopting high-speed, super-high speed or wide-wheel grinding to increase the amount of active abrasive per unit time; 2) increasing cutting depth so as to increase the length of grinding debris; 3) adopting powerful grinding to increase the mean cross-sectional area of grinding debris. Any grinding techniques adopting single or multiple methods mentioned above to improve specific material removal rate in comparison with conventional grinding can be called as high-efficiency grinding techniques. Among them, the development of high-speed/super-high speed grinding, creep-feed deep-cutting grinding, high-efficiency deep-cutting grinding, belt grinding and heavy-duty snagging has drawn most of the attentions.

When the material removal rate is fixed, the increase in grinding wheel's rotation speed causes the active abrasive amount per unit time to increase greatly, and the cutting thickness of each abrasive grain is thinned if the feed rate is fixed. Besides, material removal in superhigh speed grinding is also accompanied by a process of heat-insulating shock-induced chip formation with extremely high strain rate [1-3]. Therefore, high-speed/super-high speed grinding has the following characteristics: 1) High production efficiency. The material removal rate is multiplied and can reach as much as $2000 \mathrm{~mm}^{3} /(\mathrm{mm} \cdot \mathrm{s})$ [4-10]; 2) It improves the dynamic wearability of grains 
and increases the service life of abrasive wheel, being favorable to grinding automation. The service life of grinding wheel at the speed of $200 \mathrm{~m} / \mathrm{s}$ is twice that at $80 \mathrm{~m} / \mathrm{s}$ when the abrasive force is fixed; the service life of abrasive wheel at $200 \mathrm{~m} / \mathrm{s}$ is 7.8 times of that at $80 \mathrm{~m} / \mathrm{s}$ when the grinding efficiency is fixed [11-15]; 3) The grain cutting thickness decreases, the height of surface plastic-upheaval decreases, and the value of surface roughness decreases. The cutting debris is formed under extremely high strain rate and insulated cutting state, and the material removing mechanism changes. Thus, it can achieve high-performance machining on brittle materials and materials difficult to machine; 4) Low abrasive force and high machining precision. At the same cutting depth, the abrasive force at the grinding speed of $250 \mathrm{~m} / \mathrm{s}$ is reduced by nearly one half in comparison with that at $180 \mathrm{~m} / \mathrm{s} ; 5)$ The amount of grinding heat transferred into workpieces is reduced, which causes the grinding temperature at the workpiece surface to decrease [16]. The layer under denatured force and high temperature is thinned, and the surface integrity improves. With CBN abrasive wheel to grind steel parts at $200 \mathrm{~m} / \mathrm{s}$, the layer with surface residual stress has the depth less than $10 \mu \mathrm{m}$ [17]; 6) The excellent properties of superhard abrasive, such as high hardness and high wearability, can be fully exhibited, and high-temperature brazing-metal bonded wheel is presently a novel abrasive wheel for super-high speed grinding; 7) It is a latest grinding technique capable of achieving high efficiency and high precision simultaneously as well as performing machining on various materials and shapes.

\section{Industrial Applications}

\section{A) High efficiency deep grinding (HEDG)}

HEDG is a high-speed, high-efficiency grinding technique integrating super-high wheel rotation speed, fast feed and large cut depth. It was primarily developed in Germany in 1980s, and deep-cutting grinders with the super-high speed of 200 to $300 \mathrm{~m} / \mathrm{s}$ were developed on the basis of CBN abrasive wheel. In high-efficiency deep-cutting grinding, the cutting depth is 0.1 to $30 \mathrm{~mm}$, the workpiece velocity is 0.5 to $10 \mathrm{~m} / \mathrm{min}$, and the wheel velocity is 80 to $200 \mathrm{~m} / \mathrm{s}[18,19]$. High metal removal rate and high surface quality can be obtained with it. The surface roughness of workpieces approaches that in conventional grinding, and the metal removal rate is 100 to 1000 times higher than that in conventional grinding. German FD613 grinder can reach the feed rate of 3000 $\mathrm{mm} / \mathrm{min}$ when grinding with $\mathrm{CBN}$, a $10 \mathrm{~mm}$-wide and 30 $\mathrm{mm}$-deep rotor slot at $150 \mathrm{~m} / \mathrm{s}$ wheel velocity [20]. In U.S., the dominant development type is multi-axis $\mathrm{CNC}$ high-efficiency deep-grinding machine, and the surface quality of the hardened steel obtained through high-efficiency deep grinding using CBN formed abrasive wheel can match that of conventional grinders.

B) Super-high speed cylindrical grinding

In CNC super-high speed cylindrical grinding, CBN wheel is used to perform super-high speed, high-efficiency, high-precision grinding on the cylindrical rotary surfaces of parts such as stepped shafts and crankshafts, with the wheel cylindrical velocity of 150 to $200 \mathrm{~m} / \mathrm{s}$. Such a technique has been successfully applied in automobile industry. For example, a ductile-iron camshaft with the grinding depth of $5 \mathrm{~mm}$ from a CNC super-high speed cylindrical grinder (GCH63B, Toyota Industrial Machinery OMIC) produced in Japan achieves the special removal rate $Z_{\mathrm{W}}$ as much as $174 \mathrm{~mm}^{3} / \mathrm{mm} \cdot \mathrm{s}$, the wheel grinding ratio (G ration) can reach 33500 , and a roughcast can be ground into a finished product directly. Employing CBN abrasive wheel, a RB625 super-high speed cylindrical grinder from Guhring Automation in German can grind roughcast into a spindle in one time, and can grind off $2 \mathrm{~kg}$ of metal each minute [16].

C) Quick-point grinding

Quick-point Grinding developed in Germany in 1994 is a new application form of super-high speed grinding. Integrating three advanced technologies: $\mathrm{NC}$ flexible machining, CBN superhard abrasive and super-high speed grinding, it is mainly used to machine parts such as shafts and disks. Its wheel axis forms a certain angle against the workpiece axis in horizontal and vertical directions, shown as in Figure 1, so the wheel and workpiece form small-area point contact. Combined with continuous-path $\mathrm{NC}$ technology, it achieves both high flexibility in NC turning as well as higher efficiency and precision; moreover, the service life of abrasive wheel is extended.

The technique has been applied in industries of automobile and machine tools and has extensive application prospect. Automobile manufacturing enterprises in China also introduced this technique and related equipment in large scale, which were used to machine camshafts and gear shafts, etc., and to achieve significant economic benefits [12].

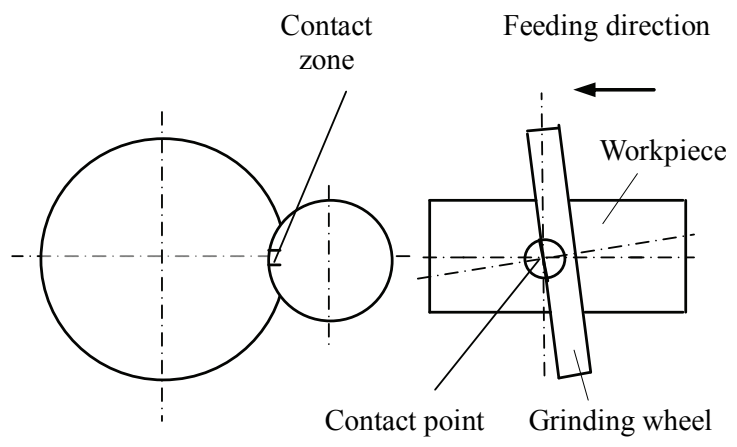

Figure 1. Contact diagram of wheel and part in quick-point grinding. 
Volkswagen Group China applied the technique to grind engine camshafts. The wheel rotation-velocity is $4300 \mathrm{r} / \mathrm{min}$, and 3000 workpieces can be ground each wheel dressing. NC quick-point grinding is also the development trend of applying semi-permanent tools to $\mathrm{NC}$ turning.

D) Super-high speed grinding of hard and brittle materials

With the development of modern hi-tech and industrialization, hard and brittle materials, such as engineering ceramics, functional ceramics, single-crystal silicon, ruby and sapphire, and optical glass, has found increasingly wide applications. Grinding hard and brittle materials with superhard abrasive under high speed/super-high speed has becomes almost the only machining method. The abrasive can penetrate deeper into workpieces under conventional grinding conditions, and grinding debris is mainly generated in the form of brittle fracture. In super-high speed grinding, the cutting thickness of single abrasive is extremely thin, so it is easier to achieve ductile grinding for hard and brittle materials.

When materials difficult to grind, such as Ni-based heat-resistant alloy and Ti-alloy, are ground at high speed, the deformation rate of grinding debris approaches the propagation speed of static plastic deformation stress waves. The plastic deformation lags and reduces the hardening tendency, so brittle machining on ductile materials can be realized. In pure-aluminum grinding at $200 \mathrm{~m} / \mathrm{s}$ (approximately the propagation speed of static stress waves of pure aluminum), the workpiece surface hardness is $50 \mathrm{HV}$, and the surface roughness $\mathrm{Ra}$ is $2.2 \mu \mathrm{m}$; when the grinding speed is at $280 \mathrm{~m} / \mathrm{s}$, the workpiece surface hardness is $45 \mathrm{HV}$, and $\mathrm{Ra}$ is $1.8 \mu \mathrm{m}$ [16].

\section{E) Powerful grinding}

Powerful grinding using radial feed or normal grinding force tens to hundreds times of those in conventional grinding to increase the average cross-sectional area of grinding debris and improve machining efficiency.

Through power grinding, desired shapes and sizes can be obtained upon the roughcast surface directly. This method is especially suitable for grinding various shaping surfaces and grooves, and generally involves high-speed powerful cylindrical grinding, creep-feed grinding and high-speed heavy-duty snagging.

High-speed powerful cylindrical grinding combining cylindrical high-speed grinding and powerful grinding, which adopts up-grinding to make grinding speed equal to the sum of wheel speed and workpiece speed. Its special removal rate can reach 8 to $40 \mathrm{~mm} / \mathrm{mm} \cdot \mathrm{s}$.

The process of high-speed cylindrical powerful grinding is generally divided into two stages: firstly, most margins are cut off with high efficiency through large radial feed; then, the radial feed is reduced to perform conventional high-speed grinding on workpieces and carry out finish machining.
Creep feed grinding technique adopting large cutting depth (1 to $30 \mathrm{~mm}$ ) and low workpiece feed rate (3 to $300 \mathrm{~mm} / \mathrm{min}$ ). It achieves high material removal rate by increasing the length of grinding debris, and is mainly used to grind grooves and shaping surfaces in surface grinding.

F) Belt grinding

Belt grinding belongs to elastic grinding and has the multi-functions of grinding, milling and polishing, etc. It is characterized by good workpiece-shape adaptability, low vibration of grinding system, low roughness of machining surface, maintenance of residual compressive stresses, low grinding temperature and resistance to workpiece burning; it also has the feature of cool grinding. Belt grinding has the advantages of flexible process, wide machining range, wide application fields, high material cutting rate, high power utilization, high belt grinding ratio, low cost for comprehensive machining, low investment and fast effect. The precision of hardbrittle material machined using ultramicro-abrasive belt with electrophoresis absorption can reach tens of nanometers, and ductile grinding can be realized. Therefore, belt grinding has been developed into an effective method for high-efficiency precision machining.

Presently, about one third of abrasive-wheel grinding has been replaced by belt grinding. The quantity of belt grinders has approached that of abrasive-wheel grinders. Their yield ratio is 49:51 in U.S., 45:55 in Germany, and 25:75 in Japan. Currently nearly 400,000 belt grinders and $950,000,000 \mathrm{~m}^{2}$ of belts are produced each year around the world.

Belt grinder is developing rapidly in directions of small size as well as high strength, high efficiency, automation, large power and wide belt. The maximum width of belt grinder has reached $4.9 \mathrm{~m}$, the maximum power has exceeded $200 \mathrm{~kW}$, and belt grinders with the high speed of $100 \mathrm{~m} / \mathrm{min}$ are in pilot production.

Advanced technologies, such as ultrasonic belt grinding, electroplated belt grinding, electrolytic belt grinding and powerful belt grinding, have emerged and been applied successively. Novel belt manufacturing technologies, such as hollow ball compounded abrasive, cork belt abrasive, multilayer coating abrasive and vitrified corundum abrasive, have been developed rapidly.

In recently years, belt grinding has been applied to precision machining and ultra-precision machining in other countries. The precision has reached micron level, and the surface roughness $\mathrm{Ra}$ has reached 0.01 to 0.25 $\mu \mathrm{m}$.

\section{Automation Intelligence and Virtualization}

CNC grinding has developed rapidly in recent years, and grinding centers capable of online measurement, automatic wheel replacement and automatic workpiece as- 
sembly and disassembly have emerged, so have grinding robots. For aspherical grinding, lapping and polishing, Computer Controlled Optical Surfacing (CCOS) is applied to control grinding-disk pressure and the relative velocity at grinding points according to required material removal quantity at a certain point on the machined surface.

With continuous track NC grinding, point grinding for cam profile, crankshaft and complex surfaces can be realized.

Intelligent grinding is currently an important research direction. Intelligent grinding system processes process information based on multi-sensor information fusion, so the information can be provided for decision making and control planning, and act on the machining process through NC controller to achieve optimal grinding control. Besides, it is also capable of self learning and maintenance. An acoustic emission sensor can monitor grinding process, finishing process, wheel abrasion and disrepair, and workpiece surface integrity effectively. Another new development in grinding sensors is the application of multi-frequency multi-sensors' grinding burning, surface hardening and hardened-layer depth in online inspection system. In Hanoverian University, a new optical measuring method combining $32 \mathrm{~mW}$ continuous laser tube, position photosensitive detector and lens was adopted to evaluate the impact of wheel shape on the stability of grinding process and to carry out online decision on the micro-characteristic information and status of abrasive wheel.

Due to the complexity of grinding process, in-depth research is still required on problems concerning the monitoring system in grinding process in respect of theory and practice. S. Malkin in U.S. also developed an intelligent abrasive wheel which collects and monitors acoustic emission signals through the sensors properly distributed and mounted on abrasive wheel and a collection and storage chip based on digital signal processor. It can perform real-time signal collection and data processing on rotating wheel and carry out computer system control and online monitoring of the grinding process and finishing process, etc. of ceramic grinding.

Simulation and prediction of grinding process and results through computer provides a new approach to grinding mechanism research. Developed in U.S., a grinding software package (GRINDSIM) has the functions of simulation, calibration and optimization, etc. In Germany, kinematics simulation was used to analyze and predict three grinding process. Three-dimensional mathe matical models describing the macro and micro morphology of abrasive wheel were built based on abrasive and wheel examination, including abrasive shape, size and distribution, and bond uplifts, etc. Multi-abrasive accumulated cutting was adopted to simulate grinding process [15].

In grinding simulating technique, vivid virtual grinding environment is established based on modeling and simulation to evaluate and predict grinding process. The built wheel morphology model is applied in the dynamic simulation of the process grinding-debris formation, energy conversion, grinding force variation, grinding-area temperature, grinding precision and ground-surface quality, and to reproduce the grinding process with the impact of grinding and geometrical parameters, grinding force and heat, grinding vibration and deformation, etc. taken into account, by which the grinding performance and effects under different conditions can be analyzed and predicted.

Molecular dynamics analysis plus grinding mechanism simulation is a new method in grinding mechanism research. Molecular dynamics is a micro method to analyze the characteristics of atomic and molecular solid models from the atomic angle. It can provide considerable information that cannot be obtained through existing experimental methods, and is a powerful tool in the research of micro-machining mechanism. In Japan in 1990, an atomic-scale cutting model was built for the micro-machining process of single-crystal copper and diamond; in 1994, simulation of machined-surface structure was performed based on molecular dynamics. The results show that accurate blade with the blunt radius of $1 / 10$ to $1 / 20$ can achieve micro-cutting, and the workpiece atoms disturbed by the ploughing cutting blade are rearranged perfectly after the cutting blade passes.

\section{Research Direction}

1) Research of basic theories and key technologies for high-speed/super-high speed grinding (super-high speed grinding, high-efficiency deep-cutting grinding and quick-point grinding): including understanding and discussions of high-speed/super-high speed grinding mechanism, surface generation and integrity control, core and key technologies and theoretical research of high-efficiency deep grinding and quick-point grinding;

2) Research of basic theories and key technologies for high-efficiency grinding: including key technologies and basic theories for powerful high-efficiency grinding process and equipment, and research of high-efficiency lowpollution stone grinding technology and theory;

3) Research of basic theories and key technologies for hard-brittle material grinding: including theories for brittle/plastic transformation under complex grinding stress, grinding damage mechanism of hard and brittle materials, damage evaluation and control, and mechanism research and implementation of deep-cutting, creep-feed and highspeed/super-high speed grinding with hard and brittle materials;

4) Research of basic theories and key technologies for intelligent examination and control of the grinding process: including research on the parameter information sensing in grinding process and multi-sensor signal fu- 
sion, and methods, theories and implementation of intelligent control in grinding process;

5) Research of basic theories and key technologies for complex surface automation and high-efficiency grinding: including research and technical implementation of complex-surface robot grinding and $\mathrm{NC}$ grinding, and that for complex-surface automatic high-efficiency grinding processes;

6) Research of basic theories and key technologies in fabrication and application of novel abrasive tools: including technologies for developing and combining novel abrasives and bond systems, structures and preparation technology innovation of novel abrasive wheel for highspeed/super-high speed and high-efficiency grinding, quantitive evaluation technology and system for the finishing and machining performance of superhard abrasives;

7) New principles, methods and process exploration for non-pollution and low-pollution grinding.

\section{Conclusions}

The basic mechanisms and the applications for the technology of high-efficiency grinding with CBN grinding wheels are presented. In addition to developments in process technology associated with high-speed and super-high grinding, quick point-grinding, high efficiency deepcut grinding, creep feed deep grinding, heavy-duty snagging and abrasive belt grinding are also analyzed. The paper concludes with a presentation of current research and future developments in the area of high-efficiency grinding. The need for high accuracy finishing and for high efficiency machining of difficult-to-machine materials is making the application of abrasive technologies increasingly important. It is concluded that high efficiency abrasive machining is a promising technology in the future.

\section{Acknowledgment}

This research was financially supported by the National Natural Science Foundation of China (50875138); the National Basic Research Program of China (2009CB 724401); the China Postdoctoral Science Foundation (20080431234); the Shandong Provincial Natural Science Foundation of China (Z2008F11); the State Key Laboratory for Manufacturing Systems Engineering's Specialized Fund; and the Specialized Construct Fund for Taishan Scholars.

\section{References}

[1] G. Warnecke and U. Zitt, "Kinematic simulation for analyzing and predicting high-performance grinding processes," Annals of CIRP, Vol. 47, No. 1, pp. 265-270,
1998.

[2] B. Varghese, S. Pa. Hare, R. Gao, C. Guo and S. Malkin, "Development of a sensor-integrated 'Intelligent' grinding wheel for in-process monitoring," Annals of the CIRP Vol. 49, No. 1, pp. 265-270, 2000.

[3] C. Koepfer, "What is single point OD grinding," Modern Machine Shop, Vol. 7, No. 70, pp. 62-99, 1997.

[4] L. Zhou, J. Shimizu, A. Muroya, et al., "Material removal mechanism beyond plastic wave propagation rate," Precision Engineering, Vol. 27, pp. 109-116, 2003.

[5] H. K. Tönshoff, T. Friemuth and J. C. Becker, "Process monitoring in grinding," Annals of the CIRP, Vol. 51, No. 2, pp. 551-569, 2002.

[6] T. Jin and G. Q. Cai, "Analytical thermal models of oblique moving heat source plane for deep grinding and cutting," Journal of Manufacturing Science and Engineering, American Society of Mechanical Engineers, Vol. 123, No. 1, pp. 185-190, 2001.

[7] H. H. Zhao, B. F. Feng and G. Q. Cai, "Study of ultrahigh speed grinding mechanism with molecular dynamics simulation," Key Engineering Materials, Vol. 259-260, pp. 302-306, 2004.

[8] B. Lin, H. Wu, H. T. Zhu and S. Y. Yu, "Study on mechanism for material removal and surface generation by molecular dynamics simulation in abrasive processes," Key Engineering Materials, Vol. 259-260, pp. 211-215, 2004.

[9] G. Warnecke and U. Zitt, "Kinematic simulation for analyzing and predicting high-performance grinding processes," Annals of CIRP, Vol. 47, No. 1, pp. 265-270, 1998.

[10] W. B. Rowe, Y. Li, X. Chen and B. Mills, "An intelligent multiagent approach for selection of grinding conditions," Annals of the CIRP, Vol. 46, No. 1, 233-238, 1997.

[11] J. F. G. de Oliveira and D. A. Dornfeld, "Application of AE contact sensing in reliable grinding monitoring," Annals of the CIRP, Vol. 50, No. 1, pp. 217-220, 2001.

[12] S. C. Aurich, O. Braun and G. Warnecke, "Development of a superabrasive grinding wheel with defined grain structure using kinematic simulation," Annals of the CIRP, Vol. 52, No. 1, pp. 275-280, 2003.

[13] H. K. Tönshoff, B. Karpuschewski and T. Mandrysch, "Grinding process achievements and their consequences on machine tools challenges and opportunities," Annals of the CIRP, Vol. 47, No. 2, pp. 651-668, 1998.

[14] H. Huang and T. C. Liu, "Experimental investigations of machining characteristics and removal mechanisms of advanced ceramics in high speed deep grinding," International Journal of Machine Tools \& Manufacture, Vol. 43, No. 8, pp. 811-823, 2003.

[15] F. Klocke, E. Brinksmeier, C. Evans, et al., "High-speed grinding-fundaments and state of the art in Europe, Japan and the USA," Annals of the CIRP, Vol. 46, No. 2, pp. 715-724, 1997.

[16] J. F. G. Oliveira and C. M. O. Valente, "Fast grinding 
process control with AE modulated power signals," Annals of the CIRP, Vol. 53, No. 1, 2004.

[17] X. P. Xu, H. Huang and W. M. Zeng, "Thermal study on the grinding of granite with superabrasive tools," Diamond and Abrasives Engineering, Vol. 3, pp. 12-17, 2003.

[18] Sunarto and Y. Ichida, "Creep feed profile grinding of Ni-based superalloys with ultrafine-polycrystalline CBN abrasive grits," Precision Engineering, Vol. 25, pp. 274-
$283,2000$.

[19] X. P. Xu, Y. Q. Yu and H. J. Xu, "Effect of grinding temperature on the surface integrity of a nickel-based superalloy," Journal of Materials Processing Technology, Vol. 129, pp. 359-363, 2002.

[20] T. W. Hwang, C. J. Evans and S. Malkin, "An investigation of high speed grinding with electroplated diamond wheels," Annals of the CIRP, Vol. 49, No. 1, pp. 245-248, 2000. 